\title{
Improving the Evaluation of Collateral Circulation by Multiphase Computed Tomography Angiography in Acute Stroke Patients Treated with Endovascular Reperfusion Therapies
}

\author{
Alvaro García-Tornel ${ }^{a} \quad V^{2}$ anssa Carvalho ${ }^{c}$ Sandra Boned $^{a}$ \\ Alan Flores $^{d}$ David Rodríguez-Luna ${ }^{a}$ Jorge Pagola ${ }^{a}$ Marian Muchada ${ }^{a}$ \\ Estela Sanjuan $^{a} \quad$ Pilar Coscojuela $^{b}$ Jesus Juega ${ }^{a}$ \\ Noelia Rodriguez-Villatoro ${ }^{a}$ Bijoy Menon ${ }^{e}$ Mayank Goyale Marc Ribó $^{a}$ \\ Alejandro Tomasello ${ }^{b}$ Carlos A. Molina ${ }^{a}$ Marta Rubiera ${ }^{a}$ \\ a Stroke Unit, Neurology Department, and b Interventional Neuroradiology Unit, \\ Radiology Department, Hospital Universitari Vall d'Hebron, Barcelona, Spain; 'Internal \\ Medicine, Hospital Luz, Lisboa, Portugal; d Neurology Department, Hospital de Clínicas \\ U.N.A. Instituto Randall, Asunción, Paraguay; ${ }^{e}$ Interventional Neuroradiology, Radiology \\ Department, University of Calgary, Calgary, Alta., Canada
}

\section{Key Words}

Acute stroke · Collateral circulation · Computed tomography angiography · Multiphase computed tomography angiography

\begin{abstract}
Good collateral circulation (CC) is associated with favorable outcomes in acute stroke, but the best technique to evaluate collaterals is controversial. Single-phase computed tomography angiography ( $\mathrm{SCTA}$ ) is widely used but lacks temporal resolution. We aim to compare CC evaluation by SCTA and multiphase CTA (MCTA) as predictors of outcome in endovascular treated patients. Methods: Consecutive endovascular treated patients with M1 middle cerebral artery (MCA) or terminal intracranial carotid artery (TICA) occlusion confirmed by SCTA were included. Two more CTA acquisitions with 8- and 16-second delays were performed for mCTA. Endovascular thrombectomy was performed independently of the CC status according to a local
\end{abstract}

Additional data with research objectives can be obtained contacting the corresponding author (mrubifu@ hotmail.com). 
García-Tornel et al.: Improving the Evaluation of Collateral Circulation by mCTA in

protocol [Alberta Stroke Program Early CT score (ASPECTS) $>6$, modified Rankin scale (mRS) score <3]. CC on SCTA and MCTA were compared. Results: 108 patients were included. Their mean age was $69.6 \pm 13$ years and their median National Institutes of Health Stroke Scale (NIHSS) score was 17 (interquartile range 8). 79 (73.1\%) had M1 MCA and 29 (26.9\%) TICA occlusions. The mean time from symptom onset to CTA was $146.8 \pm 96.5 \mathrm{~min}$. On sCTA, 50.9\% patients presented good CC vs. $57.5 \%$ on mCTA. Good CC status in both SCTA and mCTA had a lower 24-hour infarct volume ( 27.4 vs. $74.8 \mathrm{~cm}^{3}$ on sCTA, $p=0.04 ; 17.2$ vs. $97.8 \mathrm{~cm}^{3}$ on mCTA, $\mathrm{p}<0.01$ ). However, only good CC on mCTA was associated with lower 24-hour (5 vs. 8.5, $p=$ 0.04 ) and median discharge NIHSS ( 2 vs. $4.5, p=0.04$ ) scores and functional independency ( $m R S$ score $<3$ ) at 3 months (76.9 vs. $23.1 \%, p<0.01$ ). In a logistic regression model including age, NIHSS, ASPECTS and recanalization, only age (OR 0.96, 95\% CI 0.93-0.99, p = 0.02) and good CC on mCTA (OR 5, 95\% CI 1.99-12.6, p < 0.01) were independent predictors of functional outcome at 3 months. Conclusion: CC evaluation by MCTA is a better prognostic marker than CC evaluation by SCTA for clinical and functional endpoints in acute stroke patients treated with endovascular thrombectomy.

(C) 2016 S. Karger AG, Basel

\section{Introduction}

Ischemic infarcts grow over time [1]. However, previous studies have suggested that the degree of leptomeningeal collateral circulation (CC) may delay, or even prevent infarct progression [2]. Good CC has been associated with better clinical and functional outcomes [3], an increased recanalization rate [4], a lower rate of hemorrhagic transformation [5], and may extend the time window for endovascular procedures [2]. The rationale for these results is the ability of CC to maintain blood flow beyond the ischemic penumbra before recanalization is achieved, reducing the infarct core and making a good clinical outcome more likely [6]. Therefore, knowledge of the degree of CC may help in the patient selection for endovascular reperfusion therapies, and improve the accuracy of imaging and clinical outcome prediction $[7,8]$.

In the acute stroke setting, there are different techniques that assess the CC status. The classical evaluation of the CC status is performed by cerebral digital subtraction angiography (DSA), considered the reference standard. However, this is a time-consuming invasive technique, only justified in the case of endovascular reperfusion therapies. Moreover, evaluation of CC by DSA requires bilateral carotid and vertebral injections, and these diagnostic procedures may delay the reperfusion treatment [9].

CC assessment with noninvasive techniques in acute ischemic stroke has been the object of multiple studies in the last few years [3, 10-13]. Multiphase computed tomography angiography (mCTA), magnetic resonance imaging (MRI) and perfusion computed tomography (PCT) modalities and scales have been designed lately to optimize CC evaluation and guide treatment decisions [13-15]. Different PCT modalities have been designed for the assessment of CC $[3,15]$, and they have been used for reperfusion treatment decisions in acute ischemic stroke clinical trials [16]. However, these modalities need postprocessing and are affected to some extent by patient motion; moreover, more specific PCT criteria for collateral assessment are yet to be determined [3]. MRI techniques have been developed, but they are time-consuming, they may delay reperfusion therapies, and they may not be available $24 \mathrm{~h}$ in most centers [17]. Single-phase CTA (sCTA) is a widely used diagnostic tool able to quickly evaluate the presence of intracranial large-vessel occlusion. It may also allow the assessment of the global CC with a single intravenous contrast injection molding $[8,14]$. However, this technique lacks temporal resolution and may mislabel CC. 
Variability in the timing of the contrast injection and image acquisition impairs comparison between studies in addition to mislabeling true collateral status [18]. Furthermore, diverse CC scoring methods have been suggested but a standard score for the evaluation of the CC status does not exist [19].

mCTA addresses some of these concerns regarding sCTA. In this technique, in addition to a conventional SCTA, two extra cerebral image acquisitions with 8- and 16-second delays are performed. This way, the evaluation of vascular filling and CC at three different time points is possible. This mCTA CC evaluation has recently been evaluated in a cohort of 147 acute stroke patients, showing better prediction of clinical outcomes than SCTA or PCT [18]. Furthermore, the recently published ESCAPE trial (Randomized Assessment of Rapid Endovascular Treatment of Ischemic Stroke) used mCTA to select patients for the trial: only good or intermediate CC patients were included [16].

Our aim was to perform an external validation study with an independent cohort of acute anterior occlusion stroke patients treated with endovascular reperfusion therapies evaluated by sCTA and mCTA. This way, we intend to confirm that mCTA improves the accuracy of sCTA for the evaluation of CC as a predictor of vascular, radiological and clinical outcomes in acute stroke patients.

\section{Subjects and Methods}

\section{Study Population}

Consecutive acute stroke patients admitted to our Emergency Department within less than $8 \mathrm{~h}$ from symptom onset were evaluated. All received a neurological examination by a certified stroke neurologist to evaluate baseline functional status [using the modified Rankin scale (mRS)] and stroke severity [by the National Institutes of Health Stroke Scale (NIHSS)]. A non-contrast CT was performed to exclude hemorrhage and large early ischemic changes [Alberta Stroke Program Early CT score (ASPECTS) >6] and sCTA and mCTA to evaluate intracranial occlusion and CC status.

Patients with a baseline mRS score $<3$, an NIHSS score $\geq 6$ and a proximal intracranial occlusion were treated with endovascular reperfusion techniques. Those patients with an occlusion of the proximal segment of the middle cerebral artery (M1 MCA) or terminal intracranial carotid artery (TICA) were included in the study.

Early clinical improvement or deterioration was defined by a decrease or an increase of $\geq 4$ points from baseline on the NIHSS at $24 \mathrm{~h}$ [20]. Functional outcome was evaluated by the mRS at 3 months. Patients were considered functionally independent if their mRS score was $\leq 2$ [21].

\section{Neuroimaging Protocol}

On admission, patients underwent a non-contrast CT scan (Definition AS, Siemens, Erlangen, Germany) within the first $6 \mathrm{~h}$ after stroke onset. CT scans were assessed to rule out hemorrhage and assessed for the presence of early parenchymal ischemic changes using the ASPECTS score [22]. If the patient was a candidate for intravenous tissue plasminogen activator (tPA), the weight-adjusted bolus was administered immediately after non-contrast CT. mCTA was performed using the following parameters: collimator of $128 \times 0.6$ $\mathrm{mm}, 120 \mathrm{kVp}$, and $250 \mathrm{mAs}$, covering the first phase from the carina until the vertex and the second and third phases from the foramen magnum to the vertex. Acquisition was triggered using a bolus tracking (100 HU) in the aortic arch after $60 \mathrm{ml}$ of intravenous contrast injection, then the second and third phases started $4 \mathrm{~s}$ after the previous phase [18]. The first phase of mCTA was considered as the sCTA for comparison later on. Intracranial occlusion was determined in the first phase of CTA.

Collaterals were not considered for clinical decision making in the acute stroke phase, but measured off-line by a stroke neurologist and a neuroradiologist blinded to clinical data. Measurement of the CC status was visually determined by comparing backfilling arteries beyond the occluded artery to similar arteries in the opposite unaffected hemisphere. CC scores obtained by both SCTA and mCTA are described in figure 1. The interrater agreement by the intraclass correlation coefficient was 0.84 (95\% CI 0.64-0.98, p < 0.001). For statistical analysis, patients were dichotomized into good and poor CC status according to both sCTA (poor CC: 0-1, good CC: 2-3) [23] and mCTA (poor CC: 0-3, good CC: 4-5) [18] (fig. 2). 


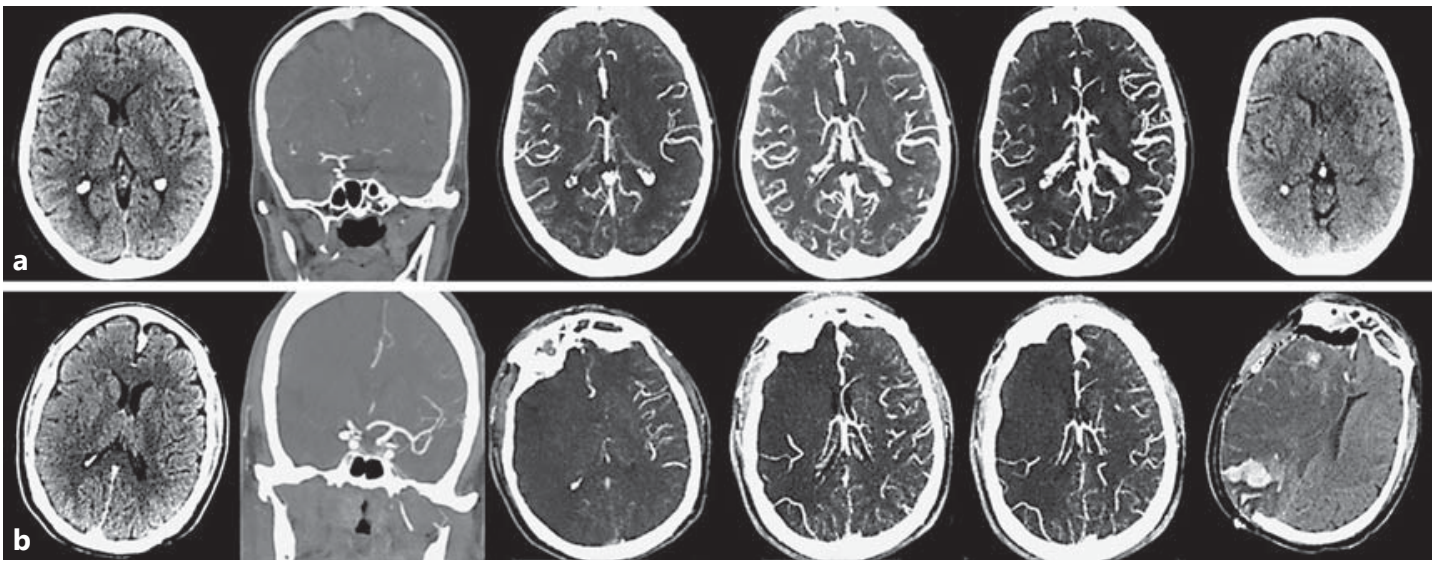

Fig. 1. a Patient with $3 \mathrm{~h}$ of left-hemisphere symptoms and an NIHSS score of 14. Unenhanced CT shows ASPECTS of 8 (insula, caudate head), a proximal left TICA occlusion is seen on CTA with good collateral flow on mCTA (one phase delay for symmetrical filling, score $4 / 5$ ). She was treated with intravenous tPA and endovascular therapy with complete recanalization but with some delay in vessel filling (TICI score $2 \mathrm{~b}$ ). CT $48 \mathrm{~h}$ after reperfusion therapy shows a small infarction in the MCA territory $\left(15 \mathrm{~cm}^{3}\right)$. b Patient with $2.5 \mathrm{~h}$ of right-hemisphere symptoms and an NIHSS score of 21. Unenhanced CT shows ASPECTS of 8 (M2-M4), a proximal right TICA occlusion is seen on CTA with poor collateral flow on mCTA (few vessels visible in any phase, score 1/5). He was treated with intravenous tPA and endovascular therapy with partial recanalization (TICI score 2a) after $4.5 \mathrm{~h}$ from symptom onset. CT $48 \mathrm{~h}$ after reperfusion therapy shows malignant ischemic infarction of the right anterior circulation territory, requiring decompressive hemicraniectomy.

All patients received endovascular reperfusion treatment performed by expert neurointerventionists. Proximal arterial occlusion was confirmed by DSA before treatment and recanalization was determined by the modified thrombolysis in cerebral ischemia (TICI) score [24]. A final TICI score of 2b-3 was defined as complete recanalization.

A 24- to 36-hour control CT was performed to detect hemorrhagic transformation of the previous ischemic tissue. If the hemorrhage was associated with clinical deterioration (NIHSS score increase $\geq 4$ ), symptomatic intracranial hemorrhage (SICH) was defined. Infarct volume was measured in the control CT scan by the $\mathrm{ABC} / 2$ rule [25].

\section{Statistical Analysis}

Categorical variables are presented as absolute values and percentages, and continuous variables as means and standard deviations, if normally distributed, or medians and interquartile ranges, if not normally distributed. Statistical significance for intergroup differences was assessed using Fisher's exact test for categorical variables and with the Student t or the Mann-Whitney U test for continuous variables. A receiver operating characteristic curve was configured to establish the infarct volume at $24 \mathrm{~h}$, which better predicted functional outcome at 3 months. Multivariate logistic regression analyses were performed for each group to determine factors that could be considered as independent predictors of favorable outcome. Variables showing a $\mathrm{p}$ value $<0.1$ in univariate analysis were included in the multivariate model. A two-sided $\mathrm{p}$ value $<0.05$ was considered significant for all tests. All statistical analyses were carried out using IBM SPSS 17.0 software.

\section{Results}

From April 2013 to October 2015, 108 patients (female 56.5\%) were included. Their mean age was $69.6 \pm 1.3$ years. Their median baseline NIHSS score was 17 (IQR, 8) and their median baseline ASPECTS was 9. Seventy-nine (73.1\%) patients presented with M1 occlusion and 29 (26.9\%) with intracranial distal or terminal ICA occlusion. Sixty (55.6\%) patients 
García-Tornel et al.: Improving the Evaluation of Collateral Circulation by MCTA in Acute Stroke Patients Treated with Endovascular Reperfusion Therapies

\begin{tabular}{|l|l|}
\hline Score & Description \\
\hline 5 & $\begin{array}{l}\text { Compared to asymptomatic contralateral hemisphere, there is no } \\
\text { delay and normal/increased prominence of peripheral } \\
\text { vessels/normal extent within the occluded arteries territory } \\
\text { within the symptomatic hemisphere }\end{array}$ \\
\hline 4 & $\begin{array}{l}\text { Compared to asymptomatic contralateral hemisphere there is a } \\
\text { delay of one phase in filling in of peripheral vessels, but } \\
\text { prominence and extent is the same }\end{array}$ \\
\hline 3 & $\begin{array}{l}\text { Compared to asymptomatic contralateral hemisphere there is a } \\
\text { delay of two phases in filling in of peripheral vessels but } \\
\text { prominence and extent is the same or there is a one phase delay } \\
\text { and decreased prominence (thinner vessels)/reduced number of } \\
\text { vessels in some part of the territory occluded }\end{array}$ \\
\hline 2 & $\begin{array}{l}\text { Compared to asymptomatic contralateral hemisphere there is a } \\
\text { delay of two phases in filling in of peripheral vessels and } \\
\text { decreased prominence and extent or a one-phase delay and some } \\
\text { regions with no vessels in some part of the territory occluded }\end{array}$ \\
\hline 1 & $\begin{array}{l}\text { Compared to asymptomatic contralateral hemisphere there are } \\
\text { just a few vessels visible in any phase within the occluded vascular } \\
\text { territory }\end{array}$ \\
\hline 0 & $\begin{array}{l}\text { Compared to asymptomatic contralateral hemisphere there are } \\
\text { no vessels in any phase within the occluded vascular territory }\end{array}$ \\
\hline
\end{tabular}

\begin{tabular}{|l|l|}
\hline Score & Description \\
\hline 3 & $\begin{array}{l}\text { Equal or }>100 \% \text { collateral supply of the occluded MCA } \\
\text { territory }\end{array}$ \\
\hline 2 & $\begin{array}{l}\text { Collateral supply filling }>50 \% \text { but }>100 \% \text { of the occluded } \\
\text { vascular territory }\end{array}$ \\
\hline 1 & $\begin{array}{l}\text { Collateral supply filling }<50 \% \text { but }>0 \% \text { of the occluded } \\
\text { vascular territory }\end{array}$ \\
\hline 0 & $\begin{array}{l}\text { Absence of collateral supply on the affected vascular } \\
\text { territory }\end{array}$ \\
\hline
\end{tabular}

Fig. 2. CC scores on SCTA and mCTA. a University of Calgary scoring on mCTA. mCTA has been developed by the University of Calgary; the patent is pending. From aspectsinstroke.com. b CC scoring on sCTA. From Tan et al. [23].

received intravenous tPA treatment before endovascular reperfusion treatment, according to European stroke guidelines. The mean time to groin puncture was $214.9 \pm 94.5 \mathrm{~min}$. All patients were treated with stent retrievers. Complete recanalization (TICI score $2 \mathrm{~b}-3$ ) was achieved in $74.8 \%$ of patients, after a mean time of $264.6 \pm 116.8$ min from stroke onset. On control CT, the mean infarct volume was $49.86 \pm 82.7 \mathrm{~cm}^{3}$. Six patients $(5.6 \%)$ presented with SICH. Fifty-four (58.4\%) patients experienced early clinical improvement, and $53(49.1 \%)$ achieved functional independency ( $m R S$ score $0-2$ ) at 3 months. The mean time from symptom onset to CTA was $146.8 \pm 96.5 \mathrm{~min}$. On sCTA, 50.9\% patients presented with good CC when compared to $57.5 \%$ on mCTA. Patients with a good CC status presented with lower baseline NIHSS scores and more probability of extracranial atherosclerotic severe stenosis or occlusion in both sCTA and mCTA. In sCTA analysis, good CC was also associated with younger age (66.5 vs. 72.8 years in poor $\mathrm{CC}, \mathrm{p}=0.01$ ) and less probability of diabetes mellitus ( $34.6 \mathrm{vs.} 65.4 \%$, $\mathrm{p}=0.04$ ) (table 1).

The recanalization rate (TICI score $2 \mathrm{~b}-3$ ) was similar in patients with good or poor CC status evaluated by both sCTA (75.5 vs. 76.9\%, $p=0.52$ ) and mCTA (78.3 vs. 73.3\%, $p=0.35$ ). In contrast, patients with a good CC status determined by SCTA and mCTA had a lower infarct volume in the 24-hour control CT (27.4 vs. $74.8 \mathrm{~cm}^{3}$ on sCTA, $p=0.04 ; 17.2$ vs. 97.8 on mCTA, $\mathrm{p}<0.01$ ). However, mCTA but not sCTA CC status was a good predictor of clinical outcomes. Good CC on mCTA was associated with a lower 24-hour (5 vs. 8.5, p = 0.04) and median discharge NIHSS score ( 2 vs. $4.5, \mathrm{p}=0.04$ ). Furthermore, patients with a good CC status evaluated by mCTA achieved more frequently functional independency (mRS score $<3$ ) at 3 months (good CC: 76.9 vs. $23.1 \%$, p < 0.01). In contrast, good CC status on sCTA also showed trends toward better early and long-term outcomes, but did not reach statistical significance (tables 2, 3).

In the poor CC status group, 5 patients presented with a CC status of $0-1(4 \%)$. Three of them died (60\%) and 2 did not achieve good functional outcome (mRS scores of 3 and 5, 
García-Tornel et al.: Improving the Evaluation of Collateral Circulation by mCTA in Acute Stroke Patients Treated with Endovascular Reperfusion Therapies

Table 1. Baseline clinical characteristics according to collateral circulation status in both the SCTA and mCTA groups

\begin{tabular}{|c|c|c|c|c|c|c|c|}
\hline & \multirow[t]{2}{*}{ Total } & \multicolumn{3}{|c|}{ CC status on sCTA } & \multicolumn{3}{|c|}{ CC status on mCTA } \\
\hline & & poor $(0-1)$ & $\operatorname{good}(2-3)$ & $\mathrm{p}$ & poor $(0-3)$ & $\operatorname{good}(4-5)$ & $\mathrm{p}$ \\
\hline Patients, n (\%) & 108 & $53(49)$ & $55(51)$ & & $45(42)$ & $63(58)$ & \\
\hline Age (mean $\pm S D$ ), years & 70 & $73 \pm 12$ & $67 \pm 14$ & 0.014 & $72 \pm 12$ & $68 \pm 14$ & 0.103 \\
\hline Male, n (\%) & 43 & $24(46)$ & $23(43$ & 0.431 & $23(51)$ & $24(39)$ & 0.157 \\
\hline Tobacco, n (\%) & $19(18)$ & $7(14)$ & $12(22)$ & 0.229 & $6(13)$ & $13(21)$ & 0.131 \\
\hline Hypertension, n (\%) & $72(67)$ & $37(71)$ & $35(65)$ & 0.312 & $31(69)$ & $41(67)$ & 0.5 \\
\hline Diabetes mellitus, n (\%) & $26(24)$ & $17(33)$ & $9(17)$ & 0.045 & $11(24)$ & $15(25)$ & 0.586 \\
\hline Hyperlipidemia, n (\%) & $57(53)$ & $30(58)$ & $27(50)$ & 0.275 & $25(55)$ & $32(53)$ & 0.453 \\
\hline Atrial fibrillation, n (\%) & $38(35)$ & $23(44)$ & $15(28)$ & 0.059 & $17(38)$ & $21(34)$ & 0.439 \\
\hline Statins, n (\%) & $40(37)$ & $21(40)$ & $19(37)$ & 0.452 & $18(40)$ & $22(36)$ & 0.566 \\
\hline Basal NIHSS score (median \pm IQR) & $17 \pm 8$ & $18 \pm 5$ & $14 \pm 9$ & 0.001 & $18 \pm 5$ & $15 \pm 8$ & 0.003 \\
\hline ASPECTS (median \pm IQR) & $9 \pm 1$ & $9 \pm 1$ & $9 \pm 1$ & 0.360 & $9 \pm 1$ & $9 \pm 1$ & 0.186 \\
\hline \multicolumn{8}{|l|}{ Occlusion site, $\%$} \\
\hline MCA & 73 & 67 & 78 & 0.452 & 71 & 74 & 0.465 \\
\hline TICA & 27 & 33 & 22 & 0.161 & 29 & 26 & 0.595 \\
\hline Time to groin $($ mean \pm SD) & $215 \pm 95$ & $212 \pm 97$ & $221 \pm 92$ & 0.630 & $221 \pm 94$ & $214 \pm 95$ & 0.724 \\
\hline
\end{tabular}

Table 2. Clinical, functional and radiological outcomes according to collateral circulation status in both the sCTA and mCTA groups

\begin{tabular}{|c|c|c|c|c|c|c|}
\hline & \multicolumn{3}{|c|}{ CC status on sCTA } & \multicolumn{3}{|c|}{ CC status on mCTA } \\
\hline & poor $(0-1)$ & $\operatorname{good}(2-3)$ & $\mathrm{p}$ & poor $(0-3)$ & $\operatorname{good}(4-5)$ & $\mathrm{p}$ \\
\hline mRS score $<3$ at 3 months, n (\%) & $21(40)$ & $31(57)$ & 0.059 & $12(27)$ & $40(65)$ & $<0.001$ \\
\hline Symptomatic hemorrhagic transformation, n (\%) & $3(6)$ & $3(6)$ & 0.652 & $4(9)$ & $2(3)$ & 0.214 \\
\hline Early clinical improvement, n (\%) & $29(59)$ & $30(60)$ & 0.548 & $22(52)$ & $37(65)$ & 0.147 \\
\hline Time to recanalization (mean $\pm \mathrm{IQR}$ ) & $243 \pm 176$ & $289 \pm 167$ & 0.070 & $260 \pm 149$ & $270 \pm 163$ & 0.680 \\
\hline Recanalization (TICI score $2 \mathrm{~b}-3$ ), $\%$ & 76 & 75 & 0.522 & 73 & 78 & 0.356 \\
\hline Infarct volume at $24 \mathrm{~h}($ mean $\pm \mathrm{SD})$ & $75 \pm 87$ & $27 \pm 72$ & 0.040 & $98 \pm 113$ & $17 \pm 21$ & $<0.001$ \\
\hline
\end{tabular}

respectively). Twelve patients (30\%) with a CC score of 2-3 achieved good functional outcome (mRS score <3). We grouped the CC scores of 0-3 together for comparison due to a low number of patients with very low CC scores.

There was no significant relationship between CC status (both mCTA and SCTA) and symptomatic hemorrhagic transformation. For mCTA, 8.9\% patients with a poor CC status and $3.3 \%$ with a good CC status presented with SICH ( $\mathrm{p}=0.398)$. For sCTA, 5.8\% patients with a poor CC and $5.7 \%$ with a good CC $(\mathrm{p}=0.652)$ presented this complication.

In a logistic regression model adjusted for baseline NIHSS score, ASPECTS and recanalization, only age (OR $0.95,95 \%$ CI $0.92-0.99, \mathrm{p}=0.02$ ) and good CC status on mCTA (OR 5, $95 \%$ CI 1.9-12.6, $\mathrm{p}<0.01$ ) emerged as independent predictors of favorable functional outcome at 3 months (table 4).

We analyzed those patients with a divergence in CC status determined by SCTA and mCTA. All 10 patients presented with poor collaterals on sCTA and good collaterals on mCTA. In this population, $80 \%$ achieved good functional outcome (mRS score $<3$ at 3 months) with no differences in baseline characteristics or treatment-related variables, which may indicate that sCTA underestimates collateral status in some patients due to its lack of temporal resolution. 
Table 3. Rates and predictive functional outcome values of patients with good and poor CC status in the sCTA and mCTA groups

\begin{tabular}{lllll}
\hline & & \multicolumn{2}{l}{3 months' functional outcome } & \multirow{2}{*}{ Predictive values } \\
\cline { 3 - 4 } & & mRS score $<3$ & mRS score $\geq 3$ & \\
\hline mCTA, n (\%) & Good $(4-5)$ & $40(66 \%)$ & $21(34 \%)$ & PPV $=0.66$ \\
& Poor $(0-3)$ & $12(27 \%)$ & $33(63 \%)$ & NPV $=0.63$ \\
\hline sCTA, n (\%) & Good $(2-3)$ & $31(56 \%)$ & $23(44 \%)$ & PPV $=0.56$ \\
& Poor $(0-1)$ & $21(40 \%)$ & $31(60 \%)$ & NPV $=0.6$ \\
\hline
\end{tabular}

PPV = Positive predictive value; NPV = negative predictive value .

Table 4. Multivariate analysis of predictors of good functional outcome in the series

\begin{tabular}{llll}
\hline & \multicolumn{3}{l}{$\begin{array}{l}\text { Good functional outcome: } \\
\text { mRS score }<3 \text { at 3 months }\end{array}$} \\
\cline { 2 - 4 } & OR & $95 \%$ CI & $\mathrm{p}$ \\
\hline Age & 0.96 & $0.93-0.99$ & 0.020 \\
CC status on sCTA & 0.92 & $0.32-2.65$ & 0.282 \\
CC status on mCTA & 5 & $1.99-12.6$ & 0.001 \\
Time to recanalization & 1 & $0.99-1.02$ & 0.507 \\
Recanalization (TICI score 2b-3) & 2.26 & $0.57-8.92$ & 0.290 \\
ASPECTS onset & 1.13 & $0.63-2.04$ & 0.988 \\
NIHSS onset & 1.03 & $0.93-1.15$ & 0.233 \\
\hline
\end{tabular}

Among the patients with a poor CC status on mCTA $(n=45)$, only $12(26.7 \%)$ achieved an mRS score $<3$ at 3 months. In this group, recanalization after endovascular status occurred in 10 cases $(83.3 \%)$, but this difference was not statistically significant $(p=0.3)$.

\section{Discussion}

Recent studies have shown that CC status evaluation with different techniques is a strong and independent prognostic marker for clinical outcomes after acute ischemic stroke [7, 8, 10, 14, 26-28]. In addition, CC status has been used to select patients for endovascular therapy [16]. However, there is no consensus about the more accurate noninvasive technique or scale for CC assessment. Furthermore, the role of the CC status in the selection of patient for endovascular treatment or the role of the potential modifying therapies to enhance collateral flow in acute ischemic stroke is unknown [3]. Our study shows that mCTA is a quick, noninvasive, accurate technique to evaluate CC status in acute ischemic stroke patients supporting another study's results comparing mCTA with other scales [18]. sCTA and mCTA CC evaluations were associated with infarct volume in our series. However, in comparison to SCTA, mCTA was also associated with early and long-term clinical outcomes, and was an independent predictor of favorable outcome together with age. It does not increase the contrast dose administered to the patients, and only increases the radiation dose by $2.4 \mathrm{mSv}$ (Siemens) and the acquisition time by $20 \mathrm{~s}$. Therefore, we strongly believe that mCTA is a more precise technique to assess CC status compared to SCTA and it may be a good option for CC evaluation in ischemic stroke patients.

The ESCAPE trial [16] showed the utility of current endovascular reperfusion treatment in patients with good or intermediate leptomeningeal CC status on mCTA. Our results are in 
García-Tornel et al.: Improving the Evaluation of Collateral Circulation by mCTA in

Acute Stroke Patients Treated with Endovascular Reperfusion Therapies

agreement with this clinical trial: patients with a good CC status achieved functional independency in $76.9 \%$ of cases. However, in patients with poor CC status, recanalization was associated with good functional outcome in 10 of 45 patients (22.2\%). Even if this is not a desirable rate, there is still a chance of good outcome in patients with a poor CC status if they recanalize (especially if the time of ischemia is short). On the other hand, 7 of 13 (53.8\%) patients with a good CC status who did not recanalize presented good functional outcome at 3 months. Therefore, more research is needed to evaluate whether the CC status may change the decision for reperfusion treatment in acute ischemic stroke.

We also found that patients with collateral assessment divergence on sCTA and mCTA (poor CC status on sCTA and good CC status on mCTA) had a high probability of good functional outcome $(80 \%$ mRS score $<3$ at 3 months). This supports the hypothesis showed in several studies that sCTA may underestimate CC [3]. Therefore, endovascular therapy decisions based on CC status measured by sCTA may be inaccurate and can lead to discarding patients for reperfusion treatment based on an incorrect evaluation of CC status.

In our series, recanalization after endovascular reperfusion treatment did not predict good functional outcome at 3 months. There was a low number of patients without complete recanalization (26 patients, $25 \%$ ). The majority of these patients, however, exhibited partial recanalization (TICI score $2 \mathrm{a}, 17$ patients, $65 \%$ of nonrecanalizers), which could have improved the outcome in this subgroup. The late time of recanalization of the series (more than $4 \mathrm{~h}$ after stroke onset) may also explain this finding.

Our study has some limitations. The number of patients is low, there is a marked heterogeneity in the study population and only patients with M1 and internal carotid artery occlusion were included, so no conclusion about the influence of CC on other stroke territories may be obtained. Also, no interrater reliability assessment of CC status using both techniques was made (only for mCTA); however, it has been proven before that there is a high correlation between different observers. A four-vessel angiography was not performed for the evaluation of the CC status in DSA to avoid a delay in reperfusion treatment, so no comparison with the CC 'gold standard' measurement was performed.

\section{Conclusions}

mCTA improves the accuracy for assessing CC status and is an independent predictor of low infarct volume and good clinical and functional outcome in acute stroke patients treated with endovascular reperfusion techniques.

\section{Disclosure Statement}

All the authors disclose no conflicts of interest related with this research. This research received no specific grant from any funding agency in the public, commercial or not-for-profit sectors.

\section{References}

1 Khatri P, Abruzzo T, Yeatts SD, Nichols C, Broderick JP, Tomsick TA: Good clinical outcome after ischemic stroke with successful revascularization is time-dependent. Neurology 2009;73:1066-1072.

2 Ribo M, Flores A, Rubiera M, Pagola J, Sargento-Freitas J, Rodriguez-Luna D, Coscojuela P, Maisterra O, Pineiro S, Romero FJ, Alvarez-Sabin J, Molina CA: Extending the time window for endovascular procedures according to collateral pial circulation. Stroke 2011;42:3465-3469.

3 Bang OY, Goyal M, Liebeskind DS: Collateral circulation in ischemic stroke: assessment tools and therapeutic strategies. Stroke 2015;46:3302-3309. 
4 Bang OY, Saver JL, Kim SJ, Kim GM, Chung CS, Ovbiagele B, Lee KH, Liebeskind DS: Collateral flow predicts response to endovascular therapy for acute ischemic stroke. Stroke 2011;42:693-699.

5 Christoforidis GA, Karakasis C, Mohammad Y, Caragine LP, Yang M, Slivka AP: Predictors of hemorrhage following intra-arterial thrombolysis for acute ischemic stroke: the role of pial collateral formation. AJNR Am J Neuroradiol 2009;30:165-170.

6 Shuaib A, Butcher K, Mohammad AA, Saqqur M, Liebeskind DS: Collateral blood vessels in acute ischaemic stroke: a potential therapeutic target. Lancet Neurol 2011;10:909-921.

7 Mangiafico S, Saia V, Nencini P, Romani I, Palumbo V, Pracucci G, Consoli A, Rosi A, Renieri L, Nappini S, Limbucci N, Inzitari D, Gensini GF: Effect of the interaction between recanalization and collateral circulation on functional outcome in acute ischaemic stroke. Interv Neuroradiol 2014;20:704-714.

8 Nambiar V, Sohn SI, Almekhlafi MA, Chang HW, Mishra S, Qazi E, Eesa M, Demchuk AM, Goyal M, Hill MD, Menon BK: CTA collateral status and response to recanalization in patients with acute ischemic stroke. AJNR Am J Neuroradiol 2014;35:884-890.

9 Christoforidis GA, Mohammad Y, Kehagias D, Avutu B, Slivka AP: Angiographic assessment of pial collaterals as a prognostic indicator following intra-arterial thrombolysis for acute ischemic stroke. AJNR Am J Neuroradiol 2005;26:1789-1797.

10 Calleja AI, Cortijo E, Garcia-Bermejo P, Gomez RD, Perez-Fernandez S, Del Monte JM, Munoz MF, FernandezHerranz R, Arenillas JF: Collateral circulation on perfusion-computed tomography-source images predicts the response to stroke intravenous thrombolysis. Eur J Neurol 2013;20:795-802.

11 Choi JY, Kim EJ, Hong JM, Lee SE, Lee JS, Lim YC, Kim HS: Conventional enhancement CT: a valuable tool for evaluating pial collateral flow in acute ischemic stroke. Cerebrovasc Dis 2011;31:346-352.

12 Frolich AM, Wolff SL, Psychogios MN, Klotz E, Schramm R, Wasser K, Knauth M, Schramm P: Time-resolved assessment of collateral flow using 4D CT angiography in large-vessel occlusion stroke. Eur Radiol 2014;24: 390-396.

13 Kim SJ, Son JP, Ryoo S, Lee MJ, Cha J, Kim KH, Kim GM, Chung CS, Lee KH, Jeon P, Bang OY: A novel magnetic resonance imaging approach to collateral flow imaging in ischemic stroke. Ann Neurol 2014;76:356-369.

14 Maas MB, Lev MH, Ay H, Singhal AB, Greer DM, Smith WS, Harris GJ, Halpern E, Kemmling A, Koroshetz WJ, Furie KL: Collateral vessels on CT angiography predict outcome in acute ischemic stroke. Stroke 2009;40:3001-3005.

15 Chen H, Wu B, Liu N, Wintermark M, Su Z, Li Y, Hu J, Zhang Y, Zhang W, Zhu G: Using standard first-pass perfusion computed tomographic data to evaluate collateral flow in acute ischemic stroke. Stroke 2015;46: 961-967.

16 Goyal M, Demchuk AM, Menon BK, Eesa M, Rempel JL, Thornton J, Roy D, Jovin TG, Willinsky RA, Sapkota BL, Dowlatshahi D, Frei DF, Kamal NR, Montanera WJ, Poppe AY, Ryckborst KJ, Silver FL, Shuaib A, Tampieri D, Williams D, Bang OY, Baxter BW, Burns PA, Choe H, Heo JH, Holmstedt CA, Jankowitz B, Kelly M, Linares G, Mandzia JL, Shankar J, Sohn SI, Swartz RH, Barber PA, Coutts SB, Smith EE, Morrish WF, Weill A, Subramaniam S, Mitha AP, Wong JH, Lowerison MW, Sajobi TT, Hill MD; Investigators ET: Randomized assessment of rapid endovascular treatment of ischemic stroke. N Engl J Med 2015;372:1019-1030.

17 Sheth KN, Terry JB, Nogueira RG, Horev A, Nguyen TN, Fong AK, Gandhi D, Prabhakaran S, Wisco D, Glenn BA, Tayal AH, Ludwig B, Hussain MS, Jovin TG, Clemmons PF, Cronin C, Liebeskind DS, Tian M, Gupta R: Advanced modality imaging evaluation in acute ischemic stroke may lead to delayed endovascular reperfusion therapy without improvement in clinical outcomes. J Neurointerv Surg 2013;5(suppl 1):i62-i65.

18 Menon BK, d'Esterre CD, Qazi EM, Almekhlafi M, Hahn L, Demchuk AM, Goyal M; Multiphase CT angiography: a new tool for the imaging triage of patients with acute ischemic stroke. Radiology 2015;275:510-520.

19 Martinon E, Lefevre PH, Thouant P, Osseby GV, Ricolfi F, Chavent A: Collateral circulation in acute stroke: assessing methods and impact: a literature review. J Neuroradiol 2014;41:97-107.

20 Tissue plasminogen activator for acute ischemic stroke. The National Institute of Neurological Disorders and Stroke rt-PA Stroke Study Group. N Engl J Med 1995;333:1581-1587.

21 van Swieten JC, Koudstaal PJ, Visser MC, Schouten HJ, van Gijn J: Interobserver agreement for the assessment of handicap in stroke patients. Stroke 1988;19:604-607.

22 Demchuk AM, Coutts SB: Alberta Stroke Program Early CT Score in acute stroke triage. Neuroimaging Clin N Am 2005;15:409-419, xii.

23 Tan JC, Dillon WP, Liu S, Adler F, Smith WS, Wintermark M: Systematic comparison of perfusion-CT and CT-angiography in acute stroke patients. Ann Neurol 2007;61:533-543.

24 Tomsick T: TIMI, TIBI, TICI: I came, I saw, I got confused. AJNR Am J Neuroradiol 2007;28:382-384.

25 Sims JR, Gharai LR, Schaefer PW, Vangel M, Rosenthal ES, Lev MH, Schwamm LH: ABC/2 for rapid clinical estimate of infarct, perfusion, and mismatch volumes. Neurology 2009;72:2104-2110.

26 Beyer SE, Thierfelder KM, von Baumgarten L, Rottenkolber M, Meinel FG, Janssen H, Ertl-Wagner B, Reiser MF, Sommer WH: Strategies of collateral blood flow assessment in ischemic stroke: prediction of the follow-up infarct volume in conventional and dynamic CTA. AJNR Am J Neuroradiol 2015;36:488-494.

27 Ernst M, Forkert ND, Brehmer L, Thomalla G, Siemonsen S, Fiehler J, Kemmling A: Prediction of infarction and reperfusion in stroke by flow- and volume-weighted collateral signal in MR angiography. AJNR Am J Neuroradiol 2015;36:275-282.

28 Sheth SA, Sanossian N, Hao Q, Starkman S, Ali LK, Kim D, Gonzalez NR, Tateshima S, Jahan R, Duckwiler GR, Saver JL, Vinuela F, Liebeskind DS; for the UCLA Collateral Investigators: Collateral flow as causative of good outcomes in endovascular stroke therapy. J Neurointerv Surg 2016;8:2-7. 